\title{
Predicting Response to Standard First-line Treatment in High-grade Serous Ovarian Carcinoma by Angiogenesis-related Genes
}

\author{
MARTA MENDIOLA ${ }^{1,2}$, ANDRÉS REDONDO ${ }^{3,4,5}$, VICTORIA HEREDIA-SOTO ${ }^{1,2}$, JESÚS HERRANZ ${ }^{6}$, \\ ALBERTO BERJÓN ${ }^{1,7}$, ALICIA HERNÁNDEZ $^{5,8}$, MARÍA MIGUEL-MARTÍN ${ }^{1}$, ROBERTO CRESPO $^{4}$, \\ JORGE BARRIUSO $^{9}$, PATRICIA CRUZ ${ }^{3}$, LAURA YÉBENES ${ }^{1,7}$, ALBERTO PELÁEZ-GARCÍA $^{1}$, \\ BEATRIZ CASTELO ${ }^{3,4}$, ANA RAMÍREZ DE MOLINA ${ }^{10}$, JAIME FELIU ${ }^{2,3,4,5,11}$ and DAVID HARDISSON ${ }^{1,5,7}$ \\ ${ }^{1}$ Molecular Pathology and Therapeutic Targets Group, Departments of ${ }^{3}$ Medical Oncology, \\ ${ }^{7}$ Pathology, and ${ }^{8}$ Gynecology and Obstetrics, and ${ }^{4}$ Translational Oncology Research Laboratory, \\ La Paz University Hospital (IdiPAZ), Madrid, Spain; \\ ${ }^{2}$ Center for Biomedical Research in the Cancer Network (Centro de Investigación Biomédica en Red de Cáncer, \\ CIBERONC), Instituto de Salud Carlos III, Madrid, Spain; \\ ${ }^{5}$ Faculty of Medicine, and ${ }^{11}$ UAM-AMGEN Chair, Autonomous University of Madrid (UAM), Madrid, Spain; \\ ${ }^{6}$ Bioinformatics Unit, and ${ }^{10}$ Molecular Oncology and Nutritional Genomics of Cancer Group, \\ IMDEA Food Institute, Madrid, Spain; \\ ${ }^{9}$ Division of Molecular and Clinical Cancer Science, School of Medical Sciences, \\ Faculty of Biology, University of Manchester, Manchester, U.K.
}

\begin{abstract}
Background/Aim: Predicting response to treatment in high-grade serous ovarian carcinoma (HGSOC) still remains a clinical challenge. The standard-of-care for firstline chemotherapy, based on a combination of carboplatin and paclitaxel, achieves a high response rate. However, the development of drug resistance is one of the major limitations to efficacy. Therefore, identification of biomarkers able to predict response to chemotherapy in patients with HGSOC is a critical step for prognosis and treatment of the disease. Several studies suggest that angiogenesis is an important process in the development of ovarian carcinoma and chemoresistance. The aim of this study was to identify a profile of angiogenesis-related genes as a biomarker for response to first-line chemotherapy in HGSOC. Materials and Methods:
\end{abstract}

Presented in part at the European Medical Oncology Meeting (Madrid, 2014) and American Association for Cancer Research (Philadelphia, 2015).

Correspondence to: David Hardisson, MD, Ph.D., Department of Pathology, Hospital Universitario La Paz, IdiPAZ, Paseo de la Castellana, 261, 28046 Madrid, Spain. Tel: +34 917277300, Fax: +34 917277049, e-mail: david.hardisson@salud.madrid.org

Key Words: Ovarian cancer, high-grade serous carcinoma, angiogenesis, gene-expression profile, chemotherapy, response prediction.
Formalin-fixed paraffin-embedded samples from 39 patients with HGSOC who underwent surgical cytoreduction and received a first-line chemotherapy with carboplatin and paclitaxel were included in this study. Expression levels of 82 angiogenesis-related genes were measured by quantitative real-time polymerase chain reaction using TaqMan lowdensity arrays. Results: Univariate analysis identified five genes [angiopoietin 1 (ANGPT1), aryl hydrocarbon receptor nuclear translocator (ARNT), CD34, epidermal growth factor (EGF) and matrix metallopeptidase 3 (MMP3)] as being statistically associated with response to treatment. Multivariable analysis by Lasso-penalized Cox regression generated a model with the combined expression of seven genes [angiotensinogen (AGT), CD34, EGF, erythropoietin receptor (EPOR), interleukin 8 (IL8), MMP3 and MMP7)]. The area under the receiver operating characteristics curve (0.679) and cross-validated Kaplan-Meier survival curves were used to estimate the accuracy of these predictors. Conclusion: An angiogenesis-related gene expression profile useful for response prediction in HGSOC was identified, supporting the important role of angiogenesis in HGSOC.

Advanced ovarian carcinoma is a leading cause of death from gynecological cancer in developed countries (1). The lethality of this disease is mainly due to the fact that most patients are diagnosed with advanced disease $(2,3)$. Moreover, despite initial effectiveness of standard treatment, 
involving surgical cytoreduction and a platinum/paclitaxel chemotherapy regime, most women will experience relapse and eventually die of their disease (4). Recent highthroughput analysis has demonstrated that high-grade serous ovarian carcinoma (HGSOC) is a different entity in the group of ovarian carcinomas (5). However, to date, there are no reliable biomarkers ready for the clinic able to identify HGSOC tumors resistant to therapy before there is radiographic or biochemical evidence of progression in the patient.

Neoangiogenesis, the formation of new vessels from preexisting vasculature, is one of the hallmarks of cancer (6-8). This is a finely regulated process, dynamically changing between pro-angiogenic and anti-angiogenic states, based on the balance of a plethora of regulators.

Specifically, in ovarian cancer it is now well-established that vascular endothelial growth factor (VEGF), the main regulator of this process, is elevated in ascites, suggesting a more intense angiogenic activity in the peritoneal cavity, and this has also been associated with poor prognosis (9). The inhibition of angiogenesis seems to be a rational approach to therapy and an antibody to VEGF, bevacizumab, has been already approved in Europe for first-line and relapse settings. Additionally, other antiangiogenic drugs were tested, including a VEGF-trap peptide, tyrosine kinase inhibitors, and angiopoietin inhibitors (10).

We and others previously described prognostic signatures associated with ovarian carcinoma, and our data support the important role of angiogenesis in ovarian carcinoma (11). In this article, we report 82 angiogenesis-related genes and their relation with response to treatment as a variable for the identification of a favorable versus unfavorable angiogenic profile.

\section{Materials and Methods}

Patient samples and clinical records. Thirty-nine non-consecutive patients with International Federation of Gynecology and Obstetrics (FIGO) stage III-IV HGOSC treated at the La Paz University Hospital, Madrid, Spain, between February 1996 and December 2003 were included in this study. The main criteria for the selection of the patients were as follows: Uniform histological type (HGOSC) in order to avoid inter-patient heterogeneity, availability of enough tumoral tissue for the molecular and immunohistochemical studies (avoiding necrotic areas, see below), and adequate follow-up data. All patients received at least six cycles of a platinum/taxane-based chemotherapy after surgery.

Baseline characteristics, such as stage, age at diagnosis and surgery outcome (optimal vs. sub-optimal), and follow-up were retrieved from the local clinical records. Progression-free survival (PFS) was defined as the period from the beginning of the treatment until disease progression or death from any cause, and overall survival (OS) was calculated from the beginning of therapy to death or last record. Optimal surgery was defined as $\leq 1 \mathrm{~cm}$ in diameter residual disease, according to the definition at the time the study started. Complete response (CR) was defined as absence of all radiographic evidence of disease after finishing surgical resection and chemotherapy.

Tissue sections stained with hematoxylin and eosin were reviewed by three gynecological subspecialty pathologists (A.B., L.Y., and D.H.). Eligible samples included more than $80 \%$ tumor cells, avoiding necrotic areas.

This study was carried out in accordance with the Helsinki Declaration, and was approved by the Ethics Committee (Comité Ético de Investigación Clínica) of the University Hospital La Paz, Madrid, Spain (code HULP: PI-1020).

RNA purification from formalin-fixed paraffin-embedded samples and real-time quantification of gene expression. Four to eight $4-\mu \mathrm{m}$ sections were used for total RNA isolation, with MasterPure RNA Purification Kit (EPICENTRE Biotechnologies, Madison, WI, USA) according to the manufacturer's instructions with minor modifications. RNA concentrations and RNA quality were measured using a Nanodrop 1000A spectrophotometer (Nanodrop Technologies, Wilmington, DE, USA). One microgram of total RNA was used for cDNA synthesis according to the protocol provided with the High Capacity Archive cDNA Reverse Transcription kit (Applied Biosystems, Foster City, CA, USA).

Eighty-two angiogenesis-related genes selected from a previous study were examined (11). Specific assays for each gene were selected and gene expression was determined by quantitative reverse transcription polymerase chain reaction with TaqMan Low Density Arrays (TLDA) in an ABI PRISM 7900 HT Sequence Detection System (Applied Biosystems). Each TLDA was configured with 96 genes in duplicate for two samples. Threshold point expression values were calculated with SDS 2.2. software (Applied Biosystems). Normalization of gene expression according to the expression of five housekeeping genes [ $18 S$, actin beta $(A C T B)$, beta- 2 microglobulin $(B 2 M)$, glyceraldehyde-3-phosphate dehydrogenase $(G A P D H)$ and glucuronidase beta $(G U S B)$ ] was performed as previously described (12). Best performing genes for normalization of raw data were selected by GeNorm Analysis software (13).

Inmunohistochemical analysis. Two 6-mm in diameter representative cores for each case were included in the tissue microarray (TMA) using a workstation (Beecher Instruments, Silver Spring, MD, USA). Five-micrometer TMA sections were obtained by a semiautomated microtome HM3508 (Microm GmBH, Walldorf, Germany), as described elsewhere (14). Tissue sections were then incubated for 60 min with the following antibodies: CD34 (\#ab8158, 1:50), epidermal growth factor (EGF) (\#ab10409, 1:500), and matrix metallopeptidase 3 (MMP3) (\#ab52915, 1:100) from Abcam (Cambridge, UK). Detection was performed with Envision Plus Detection System (Dako, Agilent Technologies, Glostrup, Denmark). Optimal conditions for each antibody were set according to distributor recommendations and adjusted with positive and negative controls. CD34 staining is usually performed as a surrogate of vascular density or presence of endothelial cells in stroma. Additionally, a specific subset of stromal cells harboring CD34 antigen, known as CD34+ stromal cells, has been recently characterized (15). The samples were classified as having low or high CD34+ stromal cells expression, with a cutoff value of $10 \%$. For EGF and MMP3, cytoplasmic staining of tumoral cells was categorized as focal when present in fewer than $20 \%$ of cells, or diffuse when higher, as previously described $(16,17)$. 
Statistical analysis. Our endpoint was to find predictive angiogenesis-related biomarkers of CR to standard therapy. Firstly, univariate Cox regression models were used to evaluate the association between gene-expression values (as a continuous variable), immunohistochemical data, and PFS and OS. The area under the curve (AUC) of the receiver operating characteristics (ROC) was also assessed to study the predictive accuracy of the Cox regression models. In an attempt to create a more powerful predictor combining more than one variable, different regression methods were used to stratify the patients into $\mathrm{CR}$ and non-CR groups, including logistic regression with Lasso and Elastic Net penalization and stepwise Akaike Information Criterion methods. To evaluate the predictive performance of the models, the AUC calculated with the cross-validated prediction score obtained with leave-one-out cross-validation (LOOCV) techniques was used (18, 19). The statistical significance of the predictor was evaluated based on the permutation distribution of the cross-validated AUC, repeating the whole LOOCV process with randomly permuted response. The $95 \%$ confidence interval (CI) of the AUC was computed with 2,000 bootstrap replicates.

We additionally explored the impact of clinical variables and gene and protein expression values on PFS and OS by log-rank test, and Kaplan-Meier plots were obtained. All analyses were performed using R Bioconductor package (Bioconductor, Open Source Software for Bioinformatics, www.bioconductor.org) and SPSS 19 software (IBM, Armonk, NY, USA), and reported $p$-values are twosided and considered significant when $p<0.05$.

\section{Results}

Descriptive statistics and univariate gene-expression analysis. The median age at diagnosis was 55 years (range $=35-82$ years). All patients had advanced disease (FIGO stage III/IV). Most of them were diagnosed with FIGO stage III (82\%), grade $3(61.5 \%)$ tumors. Optimal debulking at surgery was achieved in $36.4 \%$ of patients. However, $74 \%$ of patients achieved a CR to chemotherapy. Median PFS and OS were 17 (range=15-18) and 40 (range=24-56) months, respectively. The characteristics of the patients included in this study are summarized in Table I.

Univariate analysis of clinical and pathological variables identified optimal surgery as the only statistically significant variable for $\mathrm{CR}$ [hazard $\operatorname{ratio}(\mathrm{HR})=18.99,95 \% \mathrm{CI}=2.0$ $2548.5 p<0.05]$. As expected, all the optimally debulked patients achieved a radiological CR. Figure 1 shows survival plots for PFS and OS regarding debulking surgery status in our series. Suboptimally debulked patients showed statistically significant shorter OS $(p=0.017)$. PFS was also reduced in our series, although not significantly $(p=0.2)$.

The expression of five genes [angiopoietin 1 (ANGPT1), aryl hydrocarbon receptor nuclear translocator (ARNT), CD34, epidermal growth factor $(E G F)$ and matrix metallopeptidase 3 (MMP3)] was statistically associated with $\mathrm{CR}$ in the complete HGSOC series. Three of them, CD34, $A R N T$ and $M M P 3$, remained associated with $\mathrm{CR}$ in the subgroup of suboptimally debulked patients (Table II).
Table I. Characteristics of the patients included in the study. Percentages were calculated adjusted to the total of cases evaluated by variable to have a cumulative total of $100 \%$.

\begin{tabular}{lc}
\hline Characteristic & Value \\
\hline Age at diagnosis, years (mean, range) & $55(35-82)$ \\
FIGO stage, n (\%) & $32(82)$ \\
III & $7(18)$ \\
IV & \\
Grade, n (\%) & $15(38.5)$ \\
2 & $24(61.5)$ \\
3 & $21(63.6)$ \\
Optimal surgery, n (\%) & $12(36.4)$ \\
No & $6(-)$ \\
Yes & \\
NR & $29(74.4)$ \\
CR, n (\%) & $10(25.6)$ \\
Yes & \\
No & $15(38.5)$ \\
Relapse, n (\%) & $24(61.5)$ \\
Yes & \\
No & $25(67.6)$ \\
Died, n (\%) & $12(32.4)$ \\
Yes & $2(-)$ \\
No & \\
NR & $17(15-18)$ \\
PFS, months & \\
Mean (range) & $40(24-56)$ \\
OS, months & \\
Mean (range) & \\
\hline
\end{tabular}

CR: Complete response; FIGO: International Federation of Gynecology and Obstetrics; PFS: progression-free survival; OS: overall survival; NR: not recorded.

Additionally, we analyzed the prognostic value of these angiogenesis-related genes, finding four genes to be associated with PFS in the complete HGSOC series (ANGPT2, CD36, CD44 and EPHB2), and five with OS [ANGPT1,CD34, CD44, MMP7 and platelet-derived growth factor $\beta(P D G F B)$ (Table III).

Multivariable analysis. In an attempt to characterize a more accurate model for $\mathrm{CR}$ prediction, we combined the expression of different genes. Alternative methods for predictor selection were compared, including Elastic Net, Stepwise AIC and selection operator (Lasso), the latter being chosen (data not shown). The selected model was composed of the combined expression of seven genes [angiotensinogen $(A G T), C D 34, E G F$, erythropoietin receptor (EPOR), interleukin 8 (IL8), MMP3 and MMP7)]. The AUC of this model was $0.679(95 \% \mathrm{CI}=0.478-0.880)$ and a borderline statistical significance was found based in a permutation test ( $p$-value $=0.097)$. LOOCV and AUC were used to assess the accuracy of the model, and Kaplan-Meier curves to evaluate discrimination of survival groups (Figure 2). However, no 

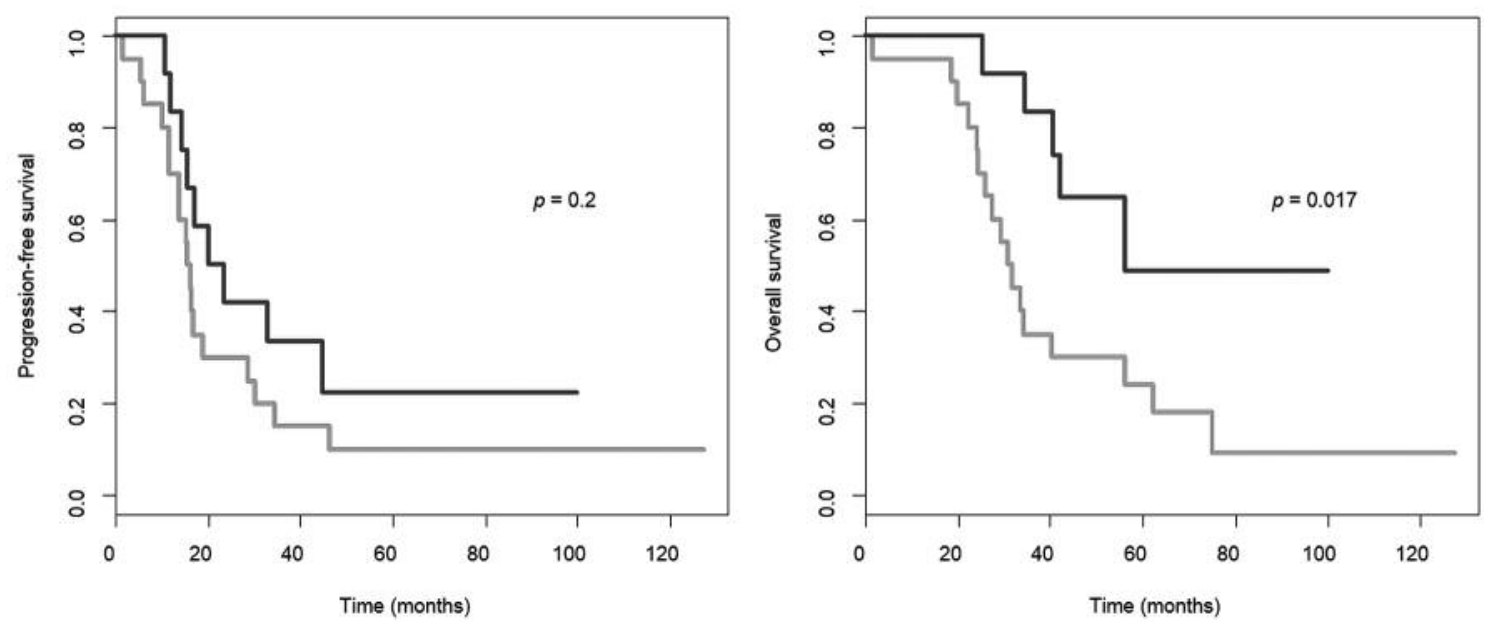

Figure 1. Kaplan-Meier curves for progression-free and overall survival of patients with high-grade serous ovarian carcinoma according to debulking status. Black lines indicate evolution of the optimally debulked patients, and grey lines show evolution of suboptimally debulked patients.

Table II. Gene expression significantly associated $(p<0.05)$ with response to treatment by univariate analysis in the complete high-grade serous ovarian carcinoma (HGSOC) series and in the subgroup with suboptimal surgery.

\begin{tabular}{|c|c|c|c|c|c|}
\hline \multirow[b]{2}{*}{ Gene symbol } & \multirow[b]{2}{*}{ Protein product } & \multicolumn{2}{|c|}{ HGSOC (All, N=39) } & \multicolumn{2}{|c|}{ Suboptimal surgery $(\mathrm{N}=21)$} \\
\hline & & OR $(95 \% \mathrm{CI})$ & $p$-Value & OR $(95 \% \mathrm{CI})$ & $p$-Value \\
\hline$A G T R 2$ & Angiotensin II receptor type 2 & $0.75(0.52-1.07)$ & 0.10 & $0.40(0.16-0.99)$ & 0.01 \\
\hline ANGPT1 & Angiopoietin 1 & $0.52(0.25-1.10)$ & 0.04 & $0.31(0.10-1.00)$ & 0.03 \\
\hline$A R N T$ & Aryl hydrocarbon receptor nuclear translocator & $0.15(0.03-0.86)$ & 0.02 & $0.12(0.01-1.04)$ & 0.03 \\
\hline$A U R K B$ & Aurora kinase $\mathrm{b}$ & $1.10(0.86-1.40)$ & 0.46 & $1.94(0.82-4.58)$ & 0.03 \\
\hline$C D 34$ & $\mathrm{CD} 34$ & $0.64(0.33-1.27)$ & 0.03 & $0.67(0.27-1.68)$ & 0.20 \\
\hline$E G F$ & Epidermal growth factor & $0.68(0.50-0.93)$ & 0.01 & $0.76(0.53-1.09)$ & 0.12 \\
\hline FLT4 & Fms related tyrosine kinase 4 & $0.62(0.28-1.40)$ & 0.24 & $0.26(0.06-1.17)$ & 0.04 \\
\hline IL8 & Interleukin 8 & $1.13(0.96-1.34)$ & 0.15 & $1.34(0.94-1.91)$ & 0.04 \\
\hline$M M P 3$ & Matrix metallopeptidase 3 & $0.59(0.38-0.94)$ & 0.01 & $0.42(0.18-0.99)$ & 0.01 \\
\hline
\end{tabular}

OR: Odds ratio; CI: confidence interval.

statistically significant differences were reached regarding PFS $(p=0.72)$ or OS $(p=0.36)$. We also applied this classification to the suboptimally debulked group, where the predictor was not able to classify patients accurately into risk categories (data not shown).

Inmunohistochemical evaluation of candidate biomarkers. Most patients (88.9\%) had low CD34 expression, and focal expression of EGF (78.6\%). In the case of MMP3, 57.6\% of cases showed focal expression, and the remaining $42.4 \%$ of tumors showed diffuse staining. None of these markers were significantly associated with response to treatment (data not shown).

\section{Discussion}

One of the main challenges in ovarian cancer research is the identification of reliable biomarkers for prediction of tumor behavior, keeping in mind that despite a very high response rate to first-line treatment, the majority of patients will experience recurrence, significantly reducing the possibility of being cured.

We decided to focus our study on angiogenesis, one of the most actively investigated hallmarks in ovarian cancer (20). Due to the high number of genes involved in this process, a single biomarker is unlike to predict benefit from therapy and, therefore, we studied 82 angiogenesis-related genes in 
Table III. Gene expression significantly associated $(p<0.05)$ with progression-free survival $(P F S)$ or overall survival $(O S)$ in the complete highgrade serous ovarian carcinoma (HGSOC) series and in the subgroup with suboptimal surgery.

\begin{tabular}{|c|c|c|c|c|c|c|c|c|c|}
\hline \multirow[b]{3}{*}{ Gene symbol } & \multirow[b]{3}{*}{ Protein product } & \multicolumn{3}{|c|}{ PFS } & \multicolumn{5}{|c|}{ OS } \\
\hline & & $\begin{array}{c}\text { HGSOC } \\
(\text { All, N=39) }\end{array}$ & & $\begin{array}{c}\text { Suboptimal } \\
\text { surgery }(\mathrm{N}=21)\end{array}$ & & $\begin{array}{c}\text { HGSOC } \\
(\text { All, N=39) }\end{array}$ & & $\begin{array}{c}\text { Suboptimal } \\
\text { surgery }(\mathrm{N}=21)\end{array}$ & \\
\hline & & $\mathrm{HR}(95 \% \mathrm{CI})$ & $p$-Value & HR $(95 \%$ CI) & $p$-Value & HR $(95 \%$ CI) & $p$-Value & HR $(95 \% \mathrm{CI})$ & $p$-Value \\
\hline$A N G P T 1$ & Angiopoietin 1 & $1.17(0.96-1.44)$ & 0.08 & $1.31(0.82-2.09)$ & 0.26 & $1.30(0.99-1.71)$ & 0.03 & $1.52(0.91-2.53)$ & 0.10 \\
\hline$A N G P T 2$ & Angiopoietin 2 & $0.59(0.36-0.97)$ & 0.03 & $0.54(0.23-1.27)$ & 0.13 & $0.60(0.34-1.04)$ & 0.06 & $0.52(0.20-1.36)$ & 0.16 \\
\hline$A U R K B$ & Aurora kinase B & $1.01(0.89-1.13)$ & 0.92 & $0.55(0.37-0.81)$ & $<0.001$ & $1.03(0.89-1.18)$ & 0.73 & $0.67(0.50-0.89)$ & 0.01 \\
\hline CD36 & CD36 & $0.66(0.45-0.97)$ & 0.03 & $0.74(0.48-1.14)$ & 0.16 & $0.81(0.54-1.23)$ & 0.32 & $0.98(0.63-1.52)$ & 0.92 \\
\hline$C D 34$ & CD34 & $1.06(0.96-1.16)$ & 0.23 & $0.73(0.42-1.26)$ & 0.25 & $1.15(0.99-1.34)$ & 0.03 & $0.67(0.37-1.19)$ & 0.17 \\
\hline$C D 44$ & $\mathrm{CD} 44$ & $0.54(0.34-0.86)$ & 0.01 & $0.57(0.35-0.92)$ & 0.01 & $0.51(0.30-0.85)$ & 0.01 & $0.53(0.32-0.90)$ & 0.01 \\
\hline$E D N R B$ & $\begin{array}{l}\text { Endothelin } \\
\text { receptor type B }\end{array}$ & $0.97(0.86-1.09)$ & 0.63 & $0.88(0.74-1.05)$ & 0.18 & $1.03(0.90-1.17)$ & 0.67 & $0.81(0.67-0.97)$ & 0.04 \\
\hline EPHB2 & EPH receptor B2 & $1.70(1.10-2.63)$ & 0.02 & $1.31(0.75-2.31)$ & 0.35 & $1.52(0.93-2.48)$ & 0.10 & $1.49(0.85-2.62)$ & 0.16 \\
\hline IL8 & Interleukin 8 & $0.93(0.86-1.01)$ & 0.09 & $0.85(0.74-0.98)$ & 0.04 & $0.98(0.89-1.08)$ & 0.67 & $0.92(0.81-1.06)$ & 0.28 \\
\hline$K D R$ & $\begin{array}{l}\text { Kinase insert } \\
\text { domain receptor }\end{array}$ & $1.11(0.81-1.53)$ & 0.49 & $0.58(0.24-1.42)$ & 0.22 & $0.97(0.70-1.34)$ & 0.86 & $0.44(0.20-0.93)$ & 0.03 \\
\hline$M M P 7$ & $\begin{array}{l}\text { Matrix metallo- } \\
\text { peptidase } 7\end{array}$ & $1.01(0.93-1.11)$ & 0.76 & $0.94(0.72-1.24)$ & 0.68 & $1.15(0.98-1.37)$ & 0.04 & $1.05(0.78-1.41)$ & 0.75 \\
\hline$P D G F B$ & $\begin{array}{l}\text { Platelet-derived } \\
\text { growth factor } \\
\text { subunit B }\end{array}$ & $1.04(0.83-1.31)$ & 0.73 & $1.16(0.79-1.69)$ & 0.44 & $1.35(1.00-1.82)$ & 0.04 & $1.36(0.87-2.15)$ & 0.16 \\
\hline \multirow{2}{*}{$\begin{array}{l}\text { THBS1 } \\
\text { VEGFC }\end{array}$} & Thrombospondin 1 & $1.19(0.69-2.05)$ & 0.53 & $1.23(0.65-2.30)$ & 0.53 & $1.45(0.73-2.89)$ & 0.29 & $2.59(1.07-6.28)$ & 0.03 \\
\hline & $\begin{array}{l}\text { Vascular endothelial } \\
\text { growth factor C }\end{array}$ & $1.04(0.90-1.19)$ & 0.6 & $1.14(0.91-1.43)$ & 0.23 & $1.04(0.89-1.20)$ & 0.62 & $1.37(1.06-1.78)$ & 0.01 \\
\hline
\end{tabular}

HR: Hazard ratio; CI: confidence interval.

order to find a classification profile. This can be pointed out as one of the strengths of this work. Focusing on the expression of a selected group of genes involved in the same process and choosing them by their biological plausibility adds credibility to our findings. In this study, the expression of five individual genes was statistically associated with response. Additionally, we also employed different statistical methodologies in order to find the most robust predictive tool. Finally, the Lasso penalized regression model was selected. This methodology offers robust internal validation, and has been used for identification of prognostic indices in different tumor types $(21,22)$. We identified a combination profile able to predict response, consisting of the expression of seven genes. The smaller number of components of the profile makes it easier to be implemented in clinical practice.

However, this model only reached borderline significance by permutation tests. This might be due to the low dimensionality of our data set (39 samples). This is one of the main limitations of this study. However, the cases were carefully selected to reduce inter-patient heterogeneity, comprising only the most prevalent ovarian carcinoma subtype, namely HGSOC. Moreover, all the patients were homogenously treated; this is particularly relevant when the primary endpoint of the study is complete response to therapy, instead of an arbitrarily established time to relapse or death. This surrogate marker has proven prognostic and predictive value $(23,24)$ and, in our opinion, it can accurately categorize patients with ovarian cancer.

For predictive modeling where the number of variables exceeds the number of cases, validation of results needs to be part of the analysis. Particularly in scenarios where an independent validation series is difficult to obtain, LOOCV can be used as an alternative to reduce the over-optimism due to sample size limitations (25). In our study, the performance of the 7-gene classifier after LOOCV had a maximum mean AUC of 0.68 , and did not reach statistical significance, probably due to the small sample size of the study.

Another question to be asked related to our findings is if the clinical scenario is favorable for developing clinical application of the profile. Bevacizumab, the first molecular targeted agent used for the treatment of ovarian carcinoma, has been actively combined in clinical trials with standard chemotherapy for first-line treatment of advanced ovarian carcinoma, and also for platinum-sensitive and resistant recurrent ovarian carcinoma (26). Results from phase III trials have demonstrated a statistically significant improvement in 


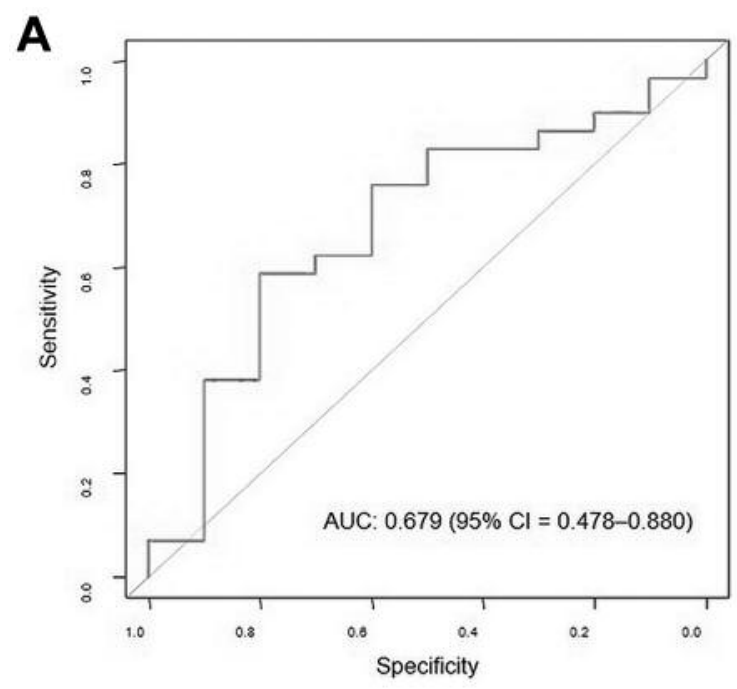

\begin{tabular}{|lc|}
\hline Gene symbol & Coefficient \\
$A G T$ & 0.087 \\
$C D 34$ & -0.248 \\
$E G F$ & -0.131 \\
$E P O R$ & -0.165 \\
$I L 8$ & 0.162 \\
$M M P 3$ & -0.342 \\
$M M P 7$ & -0.008 \\
\hline
\end{tabular}
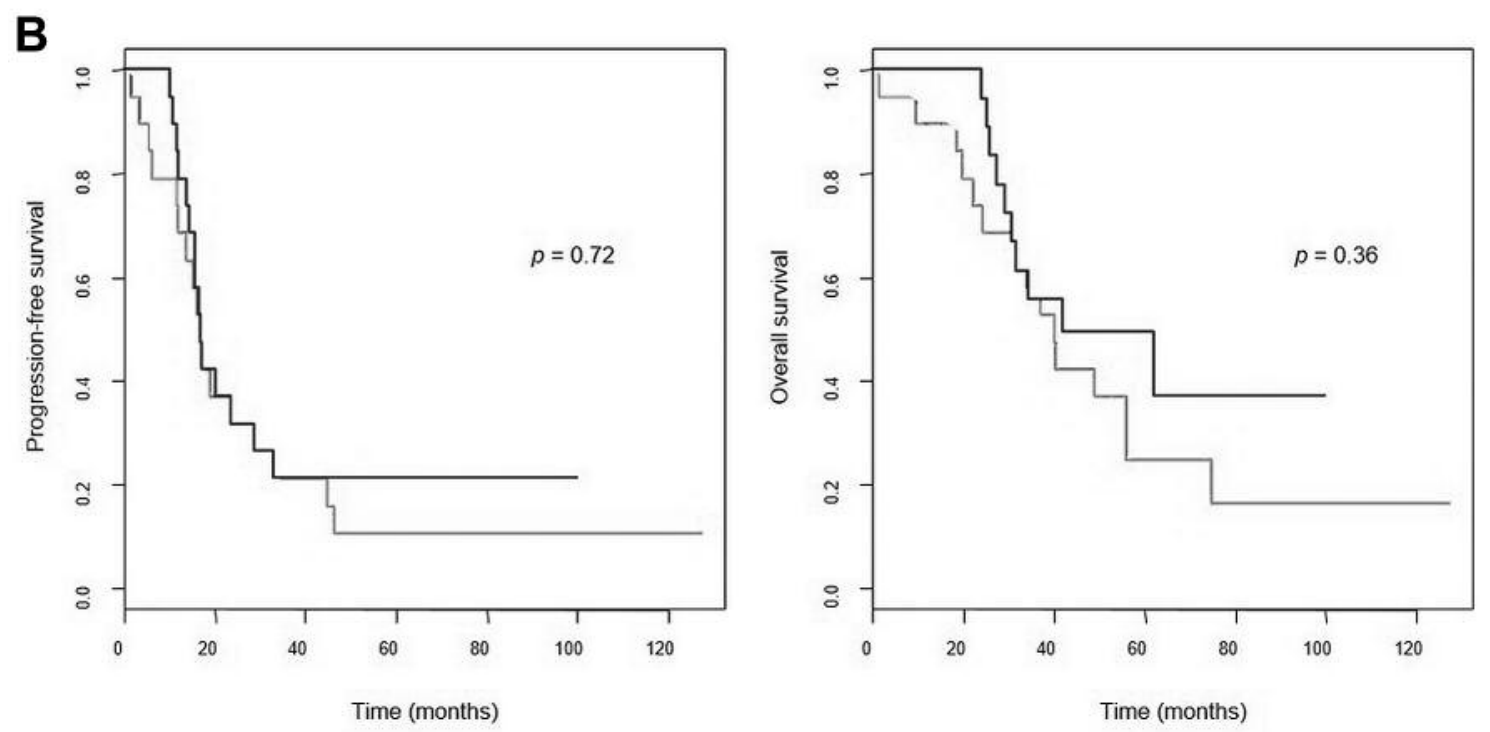

Figure 2. A: Receiver operating characteristics curve showing sensitivity and specificity of the angiogenesis-related gene model. The model was composed of the expression of the seven genes indicated at the right, including their coefficients, and area under curve (AUC). B: Kaplan-Meier curves for progression-free and overall survival. In this panel, black lines indicate evolution of patients with better prognosis, whereas grey lines show evolution of patients with poor prognosis according to the model. AGT: Angiotensinogen, CD34: CD34 molecule, EGF: epidermal growth factor, EPOR: erythropoietin receptor, IL8: interleukin 8, MMP3/7: matrix metallopeptidase 3/7.

PFS but not in OS [reviewed in (27)]. Moreover, the associated side-effects of this therapy must be considered, in particular when therapeutic success is not guaranteed. For these reasons, it would be interesting to test if the benefit of the addition of bevacizumab to the standard regime could be predicted by the angiogenesis-related profile.

Three out of the seven genes of this profile were correlated with response in the univariate analysis: EGF, MMP3 and $C D 34$. However, the expression of the proteins encoded by these genes was not related to response to treatment nor to survival in our series. The epidermal growth factor receptor (ERBB)/EGF receptor tyrosine kinase plays an important role in cell proliferation, survival, adhesion, motility, invasion and angiogenesis (28). Even though controversially, EGFR overexpression has been correlated with poor prognosis in ovarian cancer (28), and it has also been described that members of the EGF ligand family play a role in the aggressive behavior of ovarian cancer (29). Extracellular matrix components, such as MMP3, can also promote cancer progression and affect drug resistance. MMP3 has been 
previously described to be up-regulated in cellular and animal models of ovarian cancer $(30,31)$. MMP7 expression has been found to be a strong independent prognostic factor for favorable prognosis in ovarian carcinoma $(32,33)$. MMP7 together with MMP9 can generate angiostatin from plasminogen, inhibiting tumor progression by limiting angiogenesis (34). Although CD34 has been reported to be correlated with poorer PFS and OS in ovarian carcinoma, results still remain controversial $(35,36)$.

In conclusion, we identified a reduced 7 -gene profile that can be useful to stratify patients regarding response to standard treatment in HGSOC. This profile, however, should be adequately validated in a large prospective series of patients.

\section{Acknowledgements}

This work was funded by Instituto de Salud Carlos III (ISCIII) and Fondo Europeo de Desarrollo Regional (FEDER), as part of PN I+D+I 2008-2011 Program (\#PI10/630), as well as by Fundación Mututa Madrileña. VH-S is supported by a predoctoral fellowship program (\#FI11/00538) (ISCIII) and CIBERONC CB16/12/00398. This research was conducted using the IdiPAZ Biobank Resource, which we thank for its excellent technical support.

\section{References}

1 Torre LA, Islami F, Siegel RL, Ward EM and Jemal A: Global cancer in women: Burden and trends. Cancer Epidemiol Biomarkers Prev 26: 444-457, 2017.

2 Hennessy BT, Coleman RL and Markman M: Ovarian cancer. Lancet 374: 1371-1382, 2009.

3 Cannistra SA: Cancer of the ovary. N Engl J Med 351: 2519-29, 2004.

4 Giornelli GH: Management of relapsed ovarian cancer: A review. Springerplus 5: 1197, 2016.

5 Bell D, Berchuck A, Birrer M, Chien J, Cramer DW, Dao F, Dhir R, Disaia P, Gabra H, Glenn P, Godwin AK, Gross J, Hartmann L, Huang M, Huntsman DG, Iacocca M, Imielinski M, Kalloger S, Karlan BY, Levine DA, Mills GB, Morrison C, Mutch D, Olvera N, Orsulic S, Park K, Petrelli N, Rabeno B, Rader JS, Sikic BI, Smith-Mccune K, Sood AK, Bowtell D, Penny R, Testa JR, Chang K, Dinh HH, Drummond JA, Fowler G, Gunaratne P, Hawes AC, Kovar CL, Lewis LR, Morgan MB, Newsham IF, Santibanez J, Reid JG, Trevino LR, Wu YQ, Wang M, Muzny DM, Wheeler DA, Gibbs RA, Getz G, Lawrence MS, Cibulskis K, Sivachenko AY, Sougnez C, Voet D, Wilkinson J, Bloom T, Ardlie K, Fennell T, Baldwin J, Gabriel S, Lander ES, Ding L, Fulton RS, Koboldt DC, McLellan MD, Wylie T, Walker J, O'Laughlin M, Dooling DJ, Fulton L, Abbott R, Dees ND, Zhang Q, Kandoth C, Wendl M, Schierding W, Shen D, Harris CC, Schmidt H, Kalicki J, Delehaunty KD, Fronick CC, Demeter R, Cook L, Wallis JW, Lin L, Magrini VJ, Hodges JS, Eldred JM, Smith SM, Pohl CS, Vandin F, Raphael BJ, Weinstock GM, Mardis ER, Wilson RK, Meyerson M, Winckler W, Verhaak RGW, Carter SL, Mermel CH, Saksena G, Nguyen H, Onofrio RC, Hubbard D, Gupta S, Crenshaw A, Ramos AH, Chin L, Protopopov A, Zhang J, Kim TM, Perna I, Xiao Y,
Zhang H, Ren G, Sathiamoorthy N, Park RW, Lee E, Park PJ, Kucherlapati R, Absher DM, Waite L, Sherlock G, Brooks JD, Li JZ, Xu J, Myers RM, Laird PW, Cope L, Herman JG, Shen H, Weisenberger DJ, Noushmehr H, Pan F, Triche T, Berman BP, Van Den Berg DJ, Buckley J, Baylin SB, Spellman PT, Purdom E, Neuvial P, Bengtsson H, Jakkula LR, Durinck S, Han J, Dorton S, Marr H, Choi YG, Wang V, Wang NJ, Ngai J, Conboy JG, Parvin B, Feiler HS, Speed TP, Gray JW, Socci ND, Liang Y, Taylor BS, Schultz N, Borsu L, Lash AE, Brennan C, Viale A, Sander C, Ladanyi M, Hoadley KA, Meng S, Du Y, Shi Y, Li L, Turman YJ, Zang D, Helms EB, Balu S, Zhou X, Wu J, Topal MD, Hayes DN, Perou CM, Wu CJ, Shukla S, Sivachenko A, Jing R, Liu Y, Noble M, Carter H, Kim D, Karchin R, Korkola JE, Heiser LM, Cho RJ, Hu Z, Cerami E, Olshen A, Reva B, Antipin Y, Shen R, Mankoo P, Sheridan R, Ciriello G, Chang WK, Bernanke JA, Haussler D, Benz CC, Stuart JM, Benz SC, Sanborn JZ, Vaske CJ, Zhu J, Szeto C, Scott GK, Yau C, Wilkerson MD, Zhang N, Akbani R, Baggerly KA, Yung WK, Weinstein JN, Shelton T, Grimm D, Hatfield M, Morris S, Yena P, Rhodes P, Sherman M, Paulauskis J, Millis S, Kahn A, Greene JM, Sfeir R, Jensen MA, Chen J, Whitmore J, Alonso S, Jordan J, Chu A, Barker A, Compton C, Eley G, Ferguson M, Fielding P, Gerhard DS, Myles R, Schaefer C, Mills Shaw KR, Vaught J, Vockley JB, Good PJ, Guyer MS, Ozenberger B, Peterson J and Thomson E: Integrated genomic analyses of ovarian carcinoma. Nature 474: 609-615, 2011.

6 Hanahan D and Weinberg RA: Hallmarks of cancer: The next generation. Cell 144: 646-74, 2011.

7 Bergers $\mathrm{G}$ and Benjamin LE: Tumorigenesis and the angiogenic switch. Nat Rev Cancer 3: 401-410, 2003.

8 Folkman J: Tumor angiogenesis: Therapeutic implications. N Engl J Med 285: 1182-6, 1971.

9 Bamias A, Pignata S and Pujade-Lauraine E: Angiogenesis: A promising therapeutic target for ovarian cancer. Crit Rev Oncol Hematol 84: 314-326, 2012.

10 Aravantinos G and Pectasides D: Bevacizumab in combination with chemotherapy for the treatment of advanced ovarian cancer: A systematic review. J Ovarian Res 7: 57, 2014.

11 Mendiola M, Barriuso J, Redondo A, Mariño-Enríquez A, Madero R, Espinosa E, Vara JAF, Sánchez-Navarro I, Hernández-Cortes G, Zamora P, Pérez-Fernández E, MiguelMartín M, Suárez A, Palacios J, González-Barón M and Hardisson D: Angiogenesis-related gene expression profile with independent prognostic value in advanced ovarian carcinoma. PLoS One 3: e4051, 2008.

12 Bachet J-B, Tabone-Eglinger S, Dessaux S, Besse A, BrahimiAdouane S, Emile J-F, Blay J-Y and Alberti L: Gene expression patterns of hemizygous and heterozygous KIT mutations suggest distinct oncogenic pathways: A study in NIH3T3 cell lines and GIST samples. PLoS One 8: e61103, 2013.

13 Vandesompele J, De Preter K, Pattyn ilip, Poppe B, Van Roy N, De Paepe A and Speleman F: Accurate normalization of realtime quantitative RT-PCR data by geometric averaging of multiple internal control genes. Genome Biol 3: 34-1, 2002.

14 Mendiola M, Barriuso J, Mariño-Enríquez A, Redondo A, Domínguez-Cáceres A, Hernández-Cortés G, Pérez-Fernández E, Sánchez-Navarro I, Vara JAF, Suárez A, Espinosa E, González-Barón M, Palacios J and Hardisson D: Aurora kinases as prognostic biomarkers in ovarian carcinoma. Hum Pathol 40: 631-8, 2009. 
15 Díaz-Flores L, Gutiérrez R, García MP, Sáez FJ, Díaz-Flores L, Valladares F and Madrid JF: CD34+ stromal cells/fibroblasts/ fibrocytes/telocytes as a tissue reserve and a principal source of mesenchymal cells. Location, morphology, function and role in pathology. Histol Histopathol 29: 831-70, 2014.

16 Raja UM, Gopal G, Shirley S, Ramakrishnan AS and Rajkumar $\mathrm{T}$ : Immunohistochemical expression and localization of cytokines/chemokines/growth factors in gastric cancer. Cytokine 89: 82-90, 2017.

17 Khelwatty S, Essapen S, Bagwan I, Green M, Seddon A and Modjtahedi H: The impact of co-expression of wild-type EGFR and its ligands determined by immunohistochemistry for response to treatment with cetuximab in patients with metastatic colorectal cancer. Oncotarget 8: 7666-7677, 2017.

18 B $\varnothing$ velstad HM, Nygård S and Borgan $\varnothing$ : Survival prediction from clinico-genomic models - a comparative study. BMC Bioinformatics 10: 1-9, 2009.

19 Heagerty PJ, Lumley T and Pepe MS: Time-dependent ROC curves for censored survival data and a diagnostic marker. Biometrics 56: 337-344, 2000.

20 Petrillo M, Nero C, Amadio G, Gallo D, Fagotti A and Scambia G: Targeting the hallmarks of ovarian cancer: The big picture. Gynecol Oncol 142: 176-183, 2016.

21 Andres SA, Brock GN and Wittliff JL: Interrogating differences in expression of targeted gene sets to predict breast cancer outcome. BMC Cancer 13: 326, 2013.

22 Mendiola M, Martínez-Marin V, Herranz J, Heredia V, Yébenes L, Zamora P, Castelo B, Pinto Á, Miguel M, Díaz E, Gámez A, Fresno JÁ, Ramírez de Molina A, Hardisson D, Espinosa E and Redondo A: Predictive value of angiogenesis-related gene profiling in patients with HER2-negative metastatic breast cancer treated with bevacizumab and weekly paclitaxel. Oncotarget 7: 24217-24227, 2016.

23 Markmann M, Rothman R, Reichman B, Hakes T, Lewis JL, Rubin S, Jones W, Almadrones L and Hoskins W: Persistent hypomagnesemia following cisplatin chemotherapy in patients with ovarian cancer. J Cancer Res Clin Oncol 117: 89-90, 1991.

24 Han Y, Huang H, Xiao Z, Zhang W, Cao Y, Qu L and Shou C: Integrated analysis of gene expression profiles associated with response of platinum/paclitaxel-based treatment in epithelial ovarian cancer. PLoS One 7: e52745, 2012.

25 Simon RM, Subramanian J, Li MC and Menezes S: Using crossvalidation to evaluate predictive accuracy of survival risk classifiers based on high-dimensional data. Brief Bioinform 12: 203-214, 2011.

26 Ruan G, Ye L, Liu G, An J, Sehouli J and Sun P: The role of bevacizumab in targeted vascular endothelial growth factor therapy for epithelial ovarian cancer: An updated systematic review and meta-analysis. Onco Targets Ther 11: 521-528, 2018.
27 Rossi L, Verrico M, Zaccarelli E, Papa A, Colonna M, Strudel $\mathrm{M}$, Vici P, Bianco V and Tomao F: Bevacizumab in ovarian cancer: A critical review of phase III studies. Oncotarget 8 : 12389-12405, 2017.

28 Lafky JM, Wilken JA, Baron AT and Maihle NJ: Clinical implications of the ErbB/epidermal growth factor (EGF) receptor family and its ligands in ovarian cancer. Biochim Biophys Acta Rev Cancer 1785: 232-265, 2008.

29 Bax HJ, Josephs DH, Pellizzari G, Spicer JF, Montes A and Karagiannis SN: Therapeutic targets and new directions for antibodies developed for ovarian cancer. MAbs 8: 1437-1455, 2016.

30 Choi JW, Ahn SE, Rengaraj D, Seo HW, Lim W, Song G and Han JY: Matrix metalloproteinase 3 is a stromal marker for chicken ovarian cancer. Oncol Lett 2: 1047-1051, 2011.

31 Januchowski R, Zawierucha P, Ruciński M, Nowicki M and Zabel M: Extracellular matrix proteins expression profiling in chemoresistant variants of the A2780 ovarian cancer cell line. Biomed Res Int 2014: 365867, 2014.

32 Köbel M, Kalloger SE, Boyd N, McKinney S, Mehl E, Palmer C, Leung S, Bowen NJ, Ionescu DN, Rajput A, Prentice LM, Miller D, Santos J, Swenerton K, Gilks CB and Huntsman D: Ovarian carcinoma subtypes are different diseases: Implications for biomarker studies. PLoS Med 5: 1749-1760, 2008.

33 Sillanpää SM, Anttila MA, Voutilainen KA, Ropponen KM, Sironen RK, Saarikoski S V. and Kosma VM: Prognostic significance of matrix metalloproteinase-7 in epithelial ovarian cancer and its relation to $\beta$-catenin expression. Int J Cancer 119: 1792-1799, 2006.

34 Patterson BC and Sang QA: Angiostatin-converting enzyme activities of human matrilysin (MMP-7) and gelatinase type B. Biochemistry 272: 28823-28825, 1997.

35 Siamakpour-Reihani S, Owzar K, Jiang C, Turner T, Deng Y, Bean SM, Horton JK, Berchuck A, Marks JR, Dewhirst MW and Alvarez Secord A: Prognostic significance of differential expression of angiogenic genes in women with high-grade serous ovarian carcinoma. Gynecol Oncol 139: 23-29, 2015.

$36 \mathrm{He}$ L, Wang Q and Zhao X: Microvessel density as a prognostic factor in ovarian cancer: A systematic review and meta-analysis. Asian Pac J Cancer Prev 16: 869-874, 2015. 